
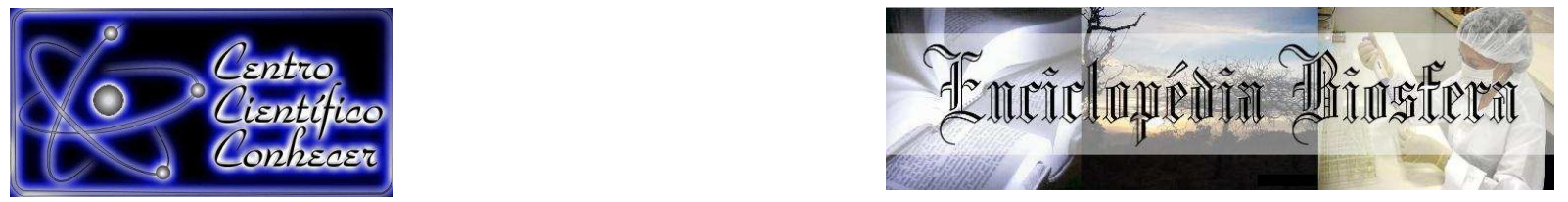

\title{
PERFIL EPIDEMIOLÓGICO E SOCIOECONÔMICO DA OCORRÊNCIA DE CASOS DE LEPTOSPIROSE EM MUNICÍPIOS DA BAIXADA FLUMINENSE, RIO DE JANEIRO, BRASIL
}

\footnotetext{
Heloiza Helena de Oliveira ${ }^{1}$, Marcos Aurélio Machado Rodrigues ${ }^{2}$, Iramar Santana dos Santos $^{3}$, Cesar Nascimento Francischetti ${ }^{4}$,

1 Entomóloga da Superintendência de Vigilância em Saúde, Secretaria Estadual de Saúde do Rio de Janeiro (heloizamorelli@gmail.com), Nova Iguaçu-RJ, Brasil.

2 Admnistrador Hospitalar na Superintendência de Vigilância em Saúde, Secretaria Estadual de Saúde do Rio de Janeiro, Nova Iguaçu-RJ, Brasil.

3 Sanitarista da Superintendência de Vigilância em Saúde, Secretaria Estadual de Saúde do Rio de Janeiro, Nova Iguaçu-RJ, Brasil.

4 Entomólogo da Superintendência de Vigilância em Saúde, Secretaria Estadual de Saúde do Rio de Janeiro (cnfrancischetti@gmail.com), Nova Iguaçu-RJ, Brasil.
}

Recebido em: 08/04/2016 - Aprovado em: 30/05/2016 - Publicado em: 20/06/2016

DOI: 10.18677/Enciclopedia_Biosfera_2016_133

\section{RESUMO}

A leptospirose é uma zoonose de distribuição mundial, e é considerada uma das epidemias urbanas freqüentes na América Latina. O objetivo do trabalho foi identificar os principais fatores socioeconômicos e epidemiológicos relacionados à ocorrência de casos de leptospirose na região da Baixada Fluminense, Rio de Janeiro, no período de 2008 a 2013. Os dados epidemiológicos dos casos confirmados de leptospirose foram obtidos no SINAN e as variáveis socioeconômicas foram obtidas no IBGE. No período de estudo foram confirmados 249 casos de leptospirose. Os indicadores socioeconômicos identificados foram: baixo IDH e índice de Gini; falta de sistema de esgotamento sanitário e abastecimento de água adequados; sistema de coleta de lixo ineficiente. A maior incidência ocorreu em Duque de Caxias. O ambiente domiciliar foi o principal local de infecção (40,8\%), sendo que 55,1\% das notificações foram deixadas em branco ou ignoradas neste campo. Os casos de leptospirose nos municípios que compõem a Baixada Fluminense estão relacionados com a desordem do crescimento urbano, com a falta de saneamento básico e má gestão dos recursos públicos.

PALAVRAS-CHAVE: Leptospira, saneamento básico, saúde ambiental.

\section{EPIDEMIOLOGIACAL AND SOCIOECONOMIC PROFILES OF LEPTOSPIROSIS CASES IN THE BAIXADA FLUMINENSE MUNICIPALITIES, RIO DE JANEIRO, BRAZIL}

\begin{abstract}
Leptospirosis is a worldwide distribution zoonosis, and is considered one of the most frequent urban epidemics in Latin America.The objective of this paper is to identify the main socio-economic and epidemiological factors related to the occurrence of leptospirosis cases in the region of Baixada Fluminense, Rio de Janeiro, from 2008 to 2013. Epidemiological data of confirmed cases of leptospirosis were obtained in SINAN and socioeconomic variables were obtained from the IBGE. During the study period 249 confirmed cases of leptospirosis were reported. The socioeconomic indicators were low
\end{abstract}

ENCICLOPÉDIA BIOSFERA, Centro Científico Conhecer - Goiânia, v.13 n.23; p.1479 2016 
$\mathrm{HDI}$ and Gini index; lack of sewage system and adequate water supply; and inefficient garbage collection system. The highest incidence occurred in Duque de Caxias. The home environment was the primary site of infection $(40.8 \%)$, with $55.1 \%$ of the notifications were left blank or ignored in this field. The leptospirosis cases in the municipalities of Baixada Fluminense are related to the disorder of urban growth, lack of basic sanitation and poor management of public resources

KEYWORDS: Leptospira, basic sanitation, environmental health

\section{INTRODUÇÃO}

A leptospirose é uma zoonose de distribuição mundial, causada por uma espiroqueta do gênero Leptospira. É uma antropozoonose que pode ser classificada de acordo com três ambientes básicos: rural, silvestre e urbano. Animais silvestres, sinantrópicos e domésticos são hospedeiros primários desta espiroqueta (OLIVEIRA et al., 2009).

Os roedores são considerados os principais reservatórios deste agente etiológico, sendo incriminados como os maiores responsáveis pela transmissão. Nos centros urbanos, Rattus norvergicus é a principal espécie transmissora, seguida de Rattus rattus e Mus musculus. Esses animais não desenvolvem a doença quando infectados e albergam a leptospira nos rins, eliminando-a viva no ambiente e contaminando água, solo e alimentos (BRASIL, 2014). Os cães também participam da cadeia de transmissão, porque após serem infectados, podem eliminar leptospiras através da urina, durante meses, sem apresentar sintomas (BATISTA et al., 2005, BLAZIUS et al., 2005, BROWN \& PRESCOTT et al., 2008). O homem é apenas hospedeiro acidental e terminal, dentro da cadeia de transmissão (BRASIL, 2014).

Apesar de ser cosmopolita, a leptospirose é mais freqüente na região tropical do que em região de clima temperado, porque as condições ambientais de calor e umidade favorecem a manutenção da bactéria no ambiente. É uma doença sazonal, com epidemias observadas em estações chuvosas ou após desastres naturais nos países de clima tropical (TASSINARI et al., 2004). O homem se infecta principalmente pelo contato direto da pele ou mucosas com água ou lama contaminadas pela urina de animais infectados, em locais com infraestrutura sanitária precária (BRASIL, 2014).

Nos últimos dez anos, vem sendo confirmada uma média anual de 3.600 casos de Leptospirose no país, e foi registrado neste período 375 óbitos em média, a cada ano (BRASIL, 2014). É considerada uma das epidemias urbanas freqüentes na América Latina (TASSINARI et al., 2004). Os sorovares infectantes têm papel importante na letalidade, assim como a precocidade do diagnóstico, do tratamento prescrito e da faixa etária do paciente. Conhecer os sorovares prevalentes em uma população e os hospedeiros que permitem a manutenção do ciclo da doença em cada região são estratégias importantes para o entendimento epidemiológico da doença, considerando que as infecções humanas resultam da exposição à urina dos animais portadores (OLIVEIRA et al., 2013). Foram confirmados no Brasil, no período de 2008 a 2013, 26.257 casos de leptospirose e uma taxa de letalidade de $8,02 \%$. Desse total de casos confirmados, 36,9\% ocorreram na região sudeste, o que mostra a maior concentração por região (OLIVEIRA et al., 2013).

$O$ processo de urbanização feito de forma intensa e desordenado propicia a criação de ambientes insalubres. A falta de saneamento básico nas grandes cidades e a freqüente exposição à contaminação ambiental durante fortes chuvas e enchentes 
são consideradas como fatores fundamentais para a ocorrência das epidemias de leptospirose em área urbana. A alta densidade demográfica contribui para o aspecto explosivo das epidemias, gerado na população que é submetida simultaneamente a condições ambientais propícias (NAVARRO et al., 2002).

No Estado do Rio de Janeiro, a Região da Baixada Fluminense é caracterizada por apresentar alta densidade populacional, com concentração de grupos populacionais em bolsões de pobreza e grandes problemas sociais. Este trabalho objetivou identificar os principais fatores epidemiológicos e socioeconômicos que estão relacionados com a ocorrência de casos de leptospirose na região da Baixada Fluminense, Estado do Rio de Janeiro, no período de 2008 a 2013.

\section{MATERIAL E MÉTODOS}

Trata-se de um estudo descritivo de fonte secundária. A Região da Baixada Fluminense é composta por 11 municípios (Belford Roxo, Duque de Caxias, Itaguaí, Japeri, Magé, Mesquita, Nilópolis, Nova Iguaçu, Queimados, São João de Meriti e Seropédica), de acordo com a regionalização adotada pela Secretaria Estadual de Saúde dentro do projeto VIGISUS (pactuado na CIB de 1999), onde foram criados os Núcleos Descentralizados de Vigilância da Saúde (NDVS), que têm como um de seus objetivos a análise da situação de saúde da região.

Através de levantamento feito no banco de dados do SINAN, foram obtidos dados epidemiológicos dos casos confirmados de leptospirose, por município de residência, no período de 2008 a 2013 e coletadas as variáveis: idade, sexo, escolaridade, e provável local de infecção.

Outras variáveis demográficas e socioeconômicas foram obtidas no banco de dados do IBGE, considerando o censo demográfico dos anos de 2000 e 2010, sendo estas: Área de Umidade Territorial, Número de Domicílios, Densidade Demográfica, Produto Interno Bruto (PIB), Índice de Desenvolvimento Humano Municipal, Índice de Gini, Taxa de Analfabetismo da População de 15 anos ou mais, Coleta de Lixo, Instalações Sanitárias e Abastecimento de Água.

\section{RESULTADOS}

No período de 2008 a 2013 ocorreram 1.714 óbitos confirmados para leptospirose no Brasil, sendo que $39,4 \%$ dos casos aconteceram na Região Sudeste. O estado do Rio de Janeiro representou $34,3 \%$ dos óbitos da região, ficando atrás apenas do estado de São Paulo (52,4\%). Na Baixada Fluminense foram confirmados 249 casos e 51 óbitos no período, sendo que 27,5\% aconteceram em Duque de Caxias, seguido de Nova Iguaçu (25,5\%) e São João de Meriti (23,5\%).

A maior incidência no período de estudo ocorreu no município de Duque de Caxias (1,6 casos/100.000 hab.), seguido de Nova Iguaçu (1,4 casos/100.000 hab.) e Belford Roxo (1,4 casos/100.000 hab.). A maior freqüência foi de casos do sexo masculino $(85,9 \%)$. Independente do sexo, a faixa etária com maior número de casos foi de 20 a 39 anos, com 34,3\% de ocorrência em Nova Iguaçu, seguida de 40 a 59 anos, com $28,1 \%$ em Duque de Caxias. O ambiente domiciliar ficou caracterizado como o principal local de infecção $(40,8 \%)$, no entanto chama a atenção o número de notificações nas quais essa informação foi ignorada ou deixada em branco $(55,1 \%)$.

Analisou-se os casos confirmados por município de residência e escolaridade, na região como um todo, observou-se que $12,4 \%$ possuíam da $5^{\underline{a}}$ a $8^{\underline{a}}$ série incompleta e 
que $11,6 \%$ tinham da $1^{\underline{a}}$ a $4^{a}$ série incompleta do ensino fundamental; Já na análise por município, Duque de Caxias foi o que apresentou a pior situação apresentando $48,4 \%$ e $69 \%$ dos casos nas respectivas séries do ensino fundamental. Com o campo escolaridade ignorado ou em branco foram identificados $55 \%$ dos casos, sendo $38 \%$ em Nova Iguaçu.

Ao serem analisadas as informações sobre as instalações sanitárias de cada um dos municípios utilizando os dados do censo 2000 (IBGE), observou-se que 31,54\% dos domicílios de Japerí não possuem nenhum tipo de rede de coleta de esgoto, sendo o mesmo lançado diretamente em vala, rio, lago ou outro escoadouro não discriminado; seguido de Magé (29,3\%) e Seropédica (28,4\%). Em Japerí 11,5\% dos domicílios não têm abastecimento de água com rede canalizada, usando poço, nascente ou outra forma para obtenção de água; e cerca de $9 \%$ dos domicílios jogam lixo em terreno baldio ou logradouro. Os municípios que apresentam melhores condições de instalações sanitárias são Nilópolis, que possui apenas $2,72 \%$ dos domicílios sem nenhum tipo de coleta de esgoto, e São João de Meriti (6,62\%).

Os municípios de Magé e Queimados são os que apresentaram o maior número de domicílios sem rede geral canalizada para abastecimento de água em pelo menos um cômodo, tendo respectivamente $44,2 \%$ e $61,5 \%$ de domicílios com rede canalizada. Em relação ao uso de fontes alternativas (poço ou nascente) ou outra forma não canalizada, Belford Roxo possui $8,9 \%$ e Japeri $11,5 \%$ dos domicílios nesta situação.

Em Japeri, apenas 55,4\% dos domicílios possui coleta de lixo, sendo que em 9\% dos domicílios os moradores jogam o lixo em terreno baldio ou logradouro. Todos os outros municípios estão acima de $75 \%$ de domicílios que possuem sistema de coleta de lixo.

Os dados referentes ao IDH, área de unidade territorial, densidade demográfica, número de domicílios e Índice de Gini estão apresentados na Tabela 1. Na Tabela 2 são apresentados os percentuais de domicílio com rede geral canalizada em pelo menos um cômodo; sem água canalizada; com coleta de lixo por serviço de limpeza; com lixo jogado em terreno baldio ou logradouro; com lançamento de esgoto em vala não discriminada, rio, lago, mar ou outro escoadouro ou sem instalação sanitária.

TABELA 1 Municípios que compõem a região da Baixada Fluminense, Rio de Janeiro, com $\mathrm{IDH}$, área da unidade territorial, densidade demográfica, número de domicílios e Índice de Gini.

\begin{tabular}{lccccc}
\hline \multicolumn{1}{c}{ Município } & IDH 2010 & $\begin{array}{c}\text { Área da unidade } \\
\text { territorial }\end{array}$ & Densidade demográfica & $\begin{array}{c}\text { Número de } \\
\text { domicílios }\end{array}$ & $\begin{array}{c}\text { Índice de } \\
\text { Gini }\end{array}$ \\
\hline Belford Roxo & 0,684 & 77,82 & $6031,4 \mathrm{hab} / \mathrm{Km} 2$ & 121.619 & 0,46 \\
Duque de Caxias & 0,711 & 467,62 & $1828,5 \mathrm{hab} / \mathrm{Km} 2$ & 219.977 & 0,49 \\
Itaguaí & 0,715 & 275,87 & $393,5 \mathrm{hab} / \mathrm{Km} 2$ & 22.969 & 0,5 \\
Japeri & 0,659 & 81,87 & $1166,4 \mathrm{hab} / \mathrm{Km} 2$ & 22.987 & 0,46 \\
Magé & 0,709 & 388,5 & $585,1 \mathrm{hab} / \mathrm{Km} 2$ & 58.097 & 0,51 \\
Mesquita & 0,737 & 19,39 & $8117,6 \mathrm{hab} / \mathrm{Km} 2$ & 0 & 0,49 \\
Nilópolis & 0,753 & 521,25 & $1527,6 \mathrm{hab} / \mathrm{Km} 2$ & 44.428 & 0,48 \\
Nova Iguaçu & 0,713 & 75,7 & $1527,6 \mathrm{hab} / \mathrm{Km} 2$ & 260.653 & 0,51 \\
Queimados & 0,68 & 1200,28 & $5265,8 \mathrm{hab} / \mathrm{Km} 2$ & 33.334 & 0,46 \\
São João de Meriti & 0,719 & 35,22 & $13024,6 \mathrm{hab} / \mathrm{Km} 2$ & 129.390 & 0,46 \\
Seropédica & 0,713 & 283,76 & $275,5 \mathrm{hab} / \mathrm{Km} 2$ & 18.114 & 0,48 \\
\hline
\end{tabular}

Fonte: IBGE 2000 e 2010 
TABELA 2 Perfil dos municípios da Baixada Fluminense, Rio de Janeiro, em relação ao fornecimento de água, sistema de coleta de lixo e rede de esgoto.

\begin{tabular}{lccccc}
\hline Municípios & $\begin{array}{c}\text { \% de domicílios } \\
\text { com rede geral } \\
\text { canalizada em } \\
\text { pelo menos um } \\
\text { cômodo }\end{array}$ & $\begin{array}{c}\text { \% de } \\
\text { domicílios } \\
\text { sem água } \\
\text { canalizada }\end{array}$ & $\begin{array}{c}\text { \% de } \\
\text { domicílios } \\
\text { com coleta } \\
\text { de lixo por } \\
\text { serviço de } \\
\text { limpeza }\end{array}$ & $\begin{array}{c}\text { \% de } \\
\text { domicílios } \\
\text { com lixo } \\
\text { jogado em } \\
\text { terreno baldio } \\
\text { ou logradouro }\end{array}$ & $\begin{array}{c}\text { \% de domicílios com } \\
\text { lançamento de esgoto } \\
\text { em vala não } \\
\text { discriminada, rio, lago, } \\
\text { ou sem instalação } \\
\text { sanitária }\end{array}$ \\
\hline B. Roxo & 69,21 & 8,9 & 85,96 & 4,77 & 16,77 \\
D. de Caxias & 65,48 & 6,4 & 86,58 & 3,55 & 18,66 \\
Itaguaí & 73,69 & 5,1 & 86,08 & 1,16 & 22,21 \\
Japeri & 57,87 & 11,5 & 55,4 & 8,96 & 31,54 \\
Magé & 44,13 & 6,8 & 80,78 & 2,37 & 29,31 \\
Mesquita & - & - & - & - & - \\
Nilópolis & 93,8 & 0,97 & 98,52 & 0,2 & 16,26 \\
Nova Iguaçu & 77,78 & 4,2 & 86,69 & 2,9 & 14,5 \\
Queimados & 61,47 & 11,7 & 85,12 & 2,38 & 6,62 \\
S. J.de Meriti & 91,35 & 1,16 & 96,13 & 1,14 & 28,39 \\
Seropédica & 83,14 & 2,52 & 77,17 & 1,62 & \\
\hline
\end{tabular}

Fonte: IBGE 2000 e 2010

No Gráfico 1 observa-se o comportamento dos casos de leptospirose em relação ao Produto Interno Bruto (PIB) municipal per capita, e no Gráfico 2 a relação entre o Índice de Desenvolvimento Humano municipal e os casos de leptospirose.

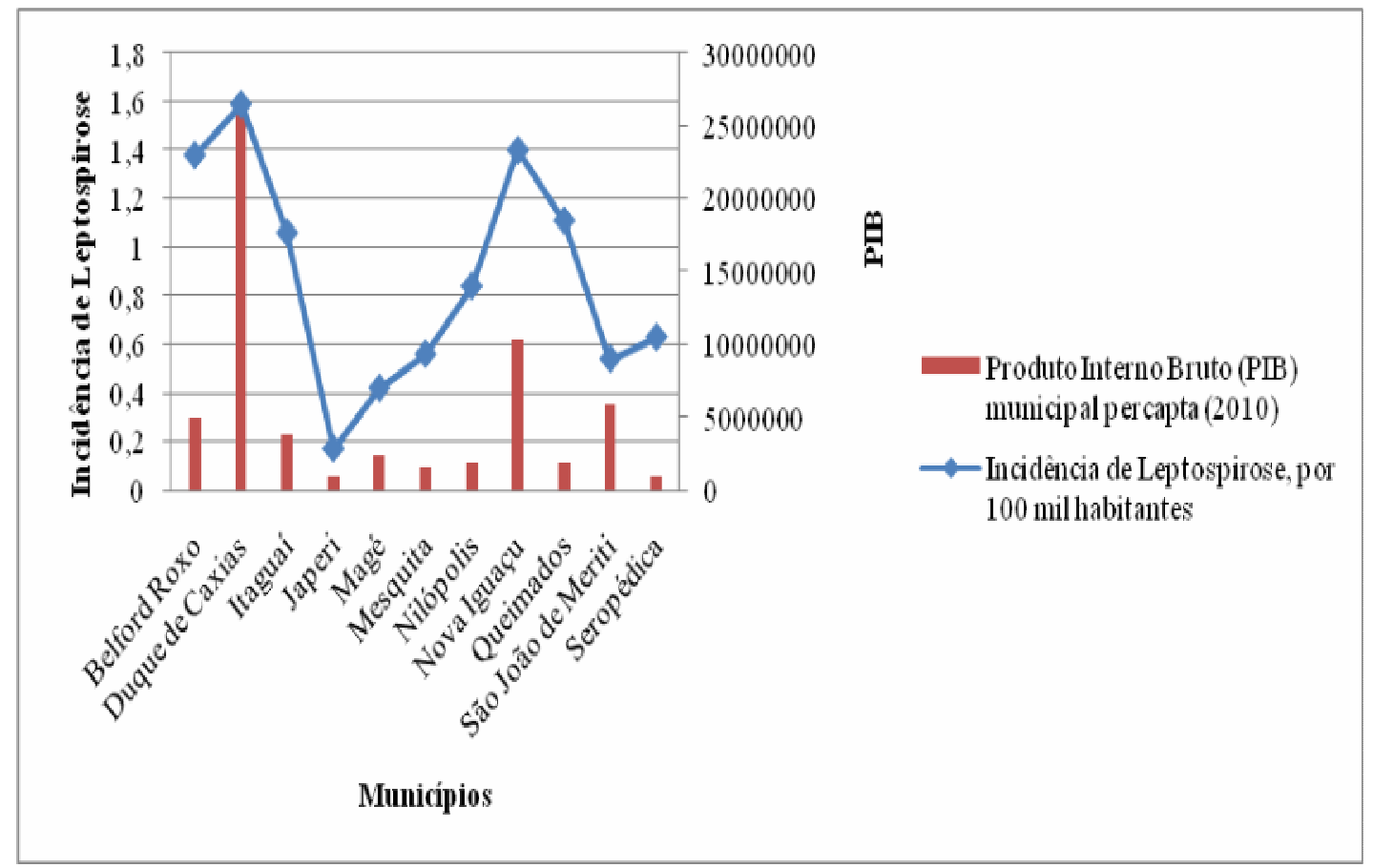

GRÁFICO 1 Incidência de leptospirose em relação ao PIB municipal per capta em 2010 nos municípios da Baixada Fluminense, estado do Rio de Janeiro. 


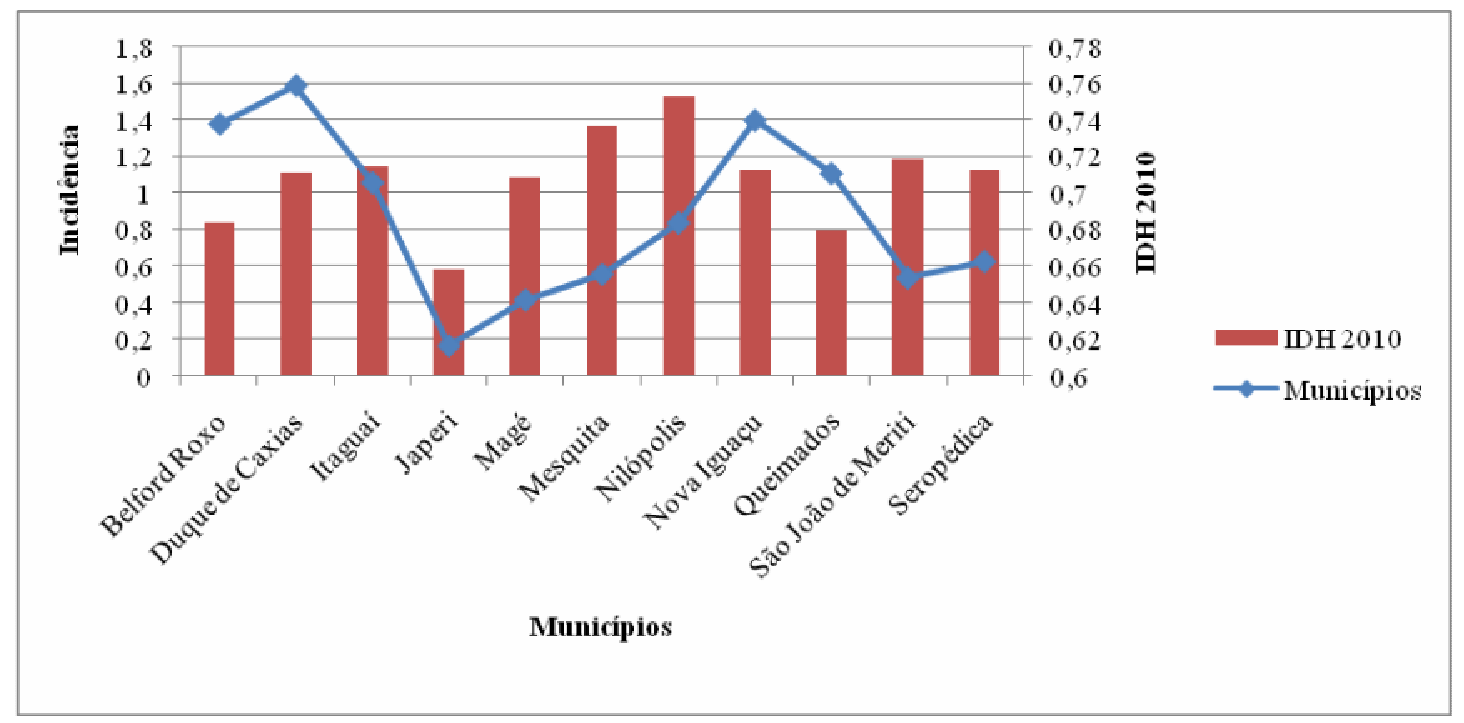

GRÁFICO 2 Incidência de leptospirose em relação ao IDH municipal em 2010 nos municípios da Baixada Fluminense, estado do Rio de Janeiro.

\section{DISCUSSÃO}

Segundo CAMPOS et al. (2011) a falta de saneamento básico nas áreas urbanas é considerado fator essencial para ocorrência de Leptospirose, o que corrobora com VASCONCELOS et al. (2012), em estudo realizado na cidade do Recife, no qual afirmaram que onde existiu a pior situação de renda, destino inadequado do lixo e falta de saneamento básico, ocorreu a pior situação de casos de Leptospirose; e com LIMA et al. (2012), que ao analisarem a distribuição espaço-temporal da leptospirose humana em Belém, também confirmaram que a doença está relacionada com precárias condições sanitárias. No entanto, no presente estudo, mesmo o município de Japeri tendo apresentado o mais baixo IDH e o pior perfil em relação às instalações sanitárias e sistema de coleta de lixo, foi o que teve a mais baixa incidência de casos de leptospirose no período estudado, contrariando a literatura. A baixa incidência de casos pode ser atribuída a falta de impermeabilização do solo na maioria das vias pública, o que contribui para o escoamento da água e inviabiliza a ocorrência de inundações e disseminação do agente etiológico.

Os fatores de risco associados à transmissão da Leptospirose dependem de características da organização espacial e das condições de vida e de trabalho da população (BARCELLUS et al., 2003). Em estudo sobre esgotamento sanitário inadequado e impactos na saúde da população (INSTITUTO TRATA BRASIL, 2010), os piores municípios (acima de 300.000 hab.) no atendimento por coleta de esgoto em 2008 foram: Duque de Caxias, São João de Meriti, Nova Iguaçu e Belford Roxo, o que não difere muito do que foi apresentado nas Tabelas 1 e 2, mostrando que a situação continua muito crítica para esses municípios e que os fatores de risco relacionados à transmissão da Leptospirose estão presentes, principalmente no que diz respeito à 
distribuição espacial da população que na maioria dos municípios se concentra em bolsões.

Observa-se que a situação sanitária dos municípios da Baixada Fluminense, apresenta a combinação da presença das doenças simbólicas do desenvolvimento juntamente com a persistência ou reemergência de enfermidades infecciosas decorrentes do subdesenvolvimento, o que , de acordo com MINAYO (2000), transpõe a ideia da transição epidemiológica pensada como uma sucessão de fases decorrentes do envelhecimento da população nos países em desenvolvimento. Em estudo feito sobre a análise espacial e sazonal da leptospirose no município de São Paulo (SOARES et al., 2010) e em uma revisão sistemática dos fatores associados à leptospirose no Brasil (PELISSARI et al., 2011) foram encontrados os mesmos dados sobre nível de escolaridade e faixa etária dos pacientes acometidos pelo agravo do presente trabalho.

Com relação ao fator econômico observou-se que apesar de o município de Duque de Caxias apresentar o maior PIB per capita, também possui a maior incidência $(1,56)$ dos casos de leptospirose no ano de 2010, seguido do município de Nova Iguaçu $(1,4)$ e Belford Roxo $(1,38)$ (Gráfico 1). Situação curiosa também é verificada quando se analisa o IDHm, onde os municípios de Duque de Caxias, Nova Iguaçu e Itaguaí apresentam na Região um IDHm acima de 0,7 e também alta incidência da doença.

Chama a atenção que as duas maiores incidências foram verificadas em municípios com o maior PIB e o inverso, com o município de menor PIB. As maiores incidências foram verificadas nos municípios com melhores condições de saneamento. Este achado vai de encontro com VASCONCELOS et al. (2012) que afirmam que quanto maior o PIB e a cobertura de esgotamento sanitário, menores serão as taxas de leptospirose e que valores muito baixos do PIB indicam a existência de segmentos sociais em precárias condições de vida.. O resultado ora encontrado é um reflexo da falta de implementação de políticas de promoção à saúde e medidas de prevenção, assim como de ações de Vigilância em Saúde Ambiental. Outra possível explicação pode ser o que foi considerado no trabalho de_TASSINARI et al. (2004), no qual os autores discutem como hipótese para esta inversão de conceitos o fato de que tais localidades podem contar com uma população, com menor resistência, e assim mais suscetíveis, e também por conta de maior sobrevida da Leptospira, que pode permanecer por longo tempo após a redução do nível de água das enchentes.

O crescimento desordenado nos centros urbanos, junto com a produção de lixo, fornecem condições ambientais favoráveis para a reprodução dos roedores, que são os principais reservatórios da doença. Um fator potencializador da disseminação da doença está presente nas fortes chuvas sazonais que provocam enchentes e inundações, podendo levar a ocorrência de epidemias de leptospirose em áreas urbanas, por ser uma condição favorável à exposição ao agente etiológico pela veiculação hídrica (TASSINARI et al., 2004). Além disso, as áreas mais baixas, influenciadas pelo relevo, podem acumular coleções de água ou interferir no curso das enchentes aumentando a intensidade dos desastres naturais (BARCELLUS et al., 2003). A região da Baixada Fluminense apresenta, em sua geografia, todas essas características, além do crescimento desordenado e falta de infraestrutura, o que poderia justificar a ocorrência dos casos. 
Não existem trabalhos na literatura sobre os possíveis reservatórios para a Leptospira sp na região estudada. BISCOLA et al. (2011), utilizando a técnica de PCR, identificaram Leptospira interrogans em serpentes de diferentes espécies e levantaram a questão do possível papel destes animais como reservatório na natureza. Outros trabalhos relatam a presença de Leptospira interrogans ou anticorpos anti-Leptospira em diferentes animais como: suíno (HAMOND et al., 2015), equino (ARTIUSHIN et al., 2012; CASELINI et al., 2012; VERNA et al., 2013; HAMOND et al., 2014; BATISTA et al., 2015; EROL et al., 2015), primata não humano (PINNA et al., 2012) e cães (LAVINSKY et al., 2012; MARTINS et al., 2011).

OLIVEIRA et al. (2013), ao fazerem uma revisão bibliográfica sobre os reservatórios da leptospirose envolvidos no ciclo de transmissão, relataram que esta pode ser encontrada em espécies domésticas, de criação, sinantrópicas e silvestres. MARTINS \& LILENBAUM (2013) descreveram o panorama da Leptospirose animal no Rio de Janeiro e demonstraram que existem importantes diferenças entre os ciclos urbanos e rurais, afirmando que a identificação dos sorogrupos predominantes e seus reservatórios animais é essencial para a compreensão das interações agentehospedeiro-ambiente. Qualquer sorovar pode determinar as diversas formas de apresentação clínica no homem (BRASIL, 2014). O desconhecimento do impacto da leptospirose diminui o reconhecimento de sua importância socioeconômica, o que resulta que medidas mais efetivas para o controle da doença sejam postergadas na agenda dos gestores da saúde pública (SOUZA et al., 2011).

De acordo com DOZSA et al. (2016), para o sucesso das ações de planejamento e gestão da saúde, urbana e ambiental, é importante o estabelecimento de mecanismos de monitoramento dos casos de leptospirose, principalmente nos locais de alagamentos recorrentes. Diante de todas essas afirmações da literatura percebe-se que conhecer os sorovares presentes no ambiente é importante para a epidemiologia da leptospirose e para o estabelecimento de políticas de saúde destinadas ao controle, e que cabe à Vigilância em Saúde Ambiental e Epidemiológica de cada um dos municípios da região promover ações para este entendimento.

$\mathrm{Na}$ Tabela 2 observa-se que, com relação ao percentual de domicílios que possuem coleta de lixo, o município de Japeri é o que apresenta a menor taxa $(55,4 \%)$ e que Nilópolis, São João de Meriti e Nova Iguaçu são aqueles que possuem as melhores condições de coleta de lixo domiciliar, respectivamente 98,5\%, 96,2\% e $89,7 \%$. Isto contudo, ao que parece, não foi fator condicionante para o agravo no município de Nilópolis, que apresentou uma incidência elevada da doença, ainda que com uma boa cobertura de coleta de lixo.

Cabe comentário sobre a situação de notificação da leptospirose, que tende a ser subnotificada, provavelmente por cursar com sintomas muitas vezes sugestivos de outras infecções, e desta forma confundir o real diagnóstico. A subnotificação da doença pode ser ocasionada por dificuldade de confirmação diagnóstica, diagnóstico incorreto e baixa detecção da enfermidade (SOUZA et al., 2011). Desta forma, a incidência de casos na Baixada Fluminense pode vir a ser maior do que a verificada. Chamou atenção o alto percentual de informação ignorada ou deixada em branco, quanto a escolaridade dos acometidos e o provável local da infecção, no SINAN, em mais da metade dos casos na Região. Tal ocorrência compromete a compreensão do real comportamento epidemiológico do agravo e interfere na implementação de ações 
para combater o problema (MACENTE \& ZANDONADE, 2010). As informações obtidas a partir dos dados dos diferentes sistemas de saúde contribuem para subsidiar decisões para políticas, planejamento, administração, monitoramento e avaliação de programas de saúde, além de servirem para a análise e avaliação epidemiológica (JORGE et al., 2010).

\section{CONCLUSÕES}

Nos municípios da Baixada Fluminense os indicadores socioeconômicos identificados foram: baixo IDH e Índice de Gini; esgotamento sanitário e abastecimento de água inadequados, e sistema de coleta de lixo ineficiente na maioria dos municípios. Duque de Caxias foi o município que apresentou a maior incidência de casos de leptospirose no período estudado. Mas fica a observação de que o resultado verificado pode estar sendo influenciado pelo número elevado de fichas do SINAN que apresentaram campos em branco ou ignorado, o que omite informações importantes para o real contexto da doença e prejudica as ações de vigilância em saúde.

Os dados analisados indicam que o perfil epidemiológico da leptospirose nos municípios que compõem a Baixada Fluminense está relacionado com a geografia local, com a desordem do crescimento urbano associado à precariedade na situação de saneamento básico e da má gestão dos recursos públicos.

\section{REFERÊNCIAS}

ARTIUSHIN, S. C.; TIMONEY, J. F.; BALASURIYA, U. B.; EROL, E.; SELLS, S. F. Realtime PCR for detection of Leptospira interrogans serovar Pomona type kennewicki in equine clinical specimens. Journal of Equine Veterinary Science, v. 32, p. S3-S95, 2012. http://www. J-evs.com/article/50737-0806(12)00624-7/pdf.

BATISTA, C.S.A.; ALVES, C.J.; VASCONCELLOS, A.S.; MORAIS, Z.M.; CLEMENTINO, I.J.; ALVES, F.A.L.; LIMA, F.S.; ARAÚJO NETO, J.O. Soroprevalência e fatores de risco para leptospirose em cães de Campina Grande, Paraíba. Arquivo Brasileiro de Medicina Veterinária, v. 57, p.179-185, 2005. http://dx.doi.org/10.1590/S0102-09352005000800008.

BARCELLUS, C.; LAMMERTH, C.B.; ALMEIDA, M.A.B., SANTOS, E. Distribuição espacial de leptospirose no Rio Grande do Sul, Brasil. Recuperando a ecologia dos estados ecológicos. Caderno de Saúde Pública, v.19, p. 1283-1292, 2003. http://www.scielo.br/pdf/CSP/v19n5/17801.pdf

BATISTA, J. S.; PAIVA, C. C. P. L.; SILVA, J. B.; COSTA, A. M.; CAVALCANTE, P. H.; PRAÇA, L. M.; OLINDA, R. G.; PAIVA, K. A. R. Avaliação de cinco casos de abortamento associado à leptospirose em éguas no Rio Grande do Norte. Revista Brasileira de Ciência Veterinária, v. 22, p. 165-170, 2015. http://dx.doi.org/10.4322/rbcv.2016.008. 
BISCOLA, N. P.; FORNAZARI, F.; SAAD, E.; RICHINI-PEREIRA, V. B.; CAMPAGNER, M. V.; LANGONI, H.; BARRAVIERA, B.; FERREIRA Jr, R. S. Serological investigation and PCR in detection of pathogenic leptospire in snakes. Pesquisa Veterinária Brasileira, v. 31, p. 806-811, 2011. http://dx.doi.org/10.1590/50100736X2011000900013.

BLAZIUS, D.R.; ROMÃO, P.R.T.; BLAZIUS, E.M.C.; SILVA, O.S. Ocorrência de cães errantes soropositivos para Leptospira spp. na cidade de Itapema, Santa Catarina, Brasil. Caderno de Saúde Pública, v.21, p.1952-1956, 2005. http://dx.doi.org/10.1590/S0102-311X2005000600046.

BRASIL. Ministério da Saúde. Secretaria de Vigilância em Saúde. Guia de Vigilância em Saúde/Ministério da Saúde, Secretaria de Vigilância em Saúde. Brasília: Ministério da Saúde, p.812, 2014.

BROWN, K.; PRESCOTT, J. Leptospirosis in yhe falily dog: a public health perspective. Canadian. Medical. Association, v.178, p.339-401, 2008. http://www.ncbi.nlm.nih.gov/pubmed/18268265PMID:18268265.

CAMPOS, H.; MARTINS, G. RESENDE, R.; SOUZA, S. M. S. Leptospirose saúde ambiental, saneamento e urbanização. Revista de Trabalhos Acadêmicoa, America do Norte, $\quad$ v. 2011. http://www.revista.universo.edu.br/index.php?journal=1 reta2\&page=article\&op=view\&pa th\%5B\%5D=352\&path\%5B\%5D=876.

CASELANI, K.; OLIVEIRA, P. R.; FERRAUDO, A. S.; LIMA-RIBEIRO, A. M. C.; GÍRIO, R. J. S. Estudo soroepidemiológico de leptospiropse em equinos utilizados para tração urbana. Revista do Instituto Adolfo Lutz, v. 71, p. 582-587, 2012. http://periodicos.ses.sp.bvs.br/pdf.rial/v71n3/v71n3a20.pdf.

DOZSA, B.; MONEGO, M. L. C. D.; KUMMER, L. Modelagem geoestatística da ocorrência de casos de leptospirose e alagamentos no município de Curitiba - PR, no ano de 2014. Holos, v. 1, p. 381-393, 2016. DOI: 10.15628/holos.2016.3857.

EROL, E.; JACKSON,C. B.; STEINMAN, M.; MEARES, K.; DONAHOE, J.; KELLY, N.; LOCKE, S.; SMITH, J. L.; CARTER, C. N. A diagnostic evaluation of real-time PCR, fluorescent antibody and microscopic agglutination tests in cases of equine leptospiral abortion. Equine Veterinary Journal, v. 47, p. 171-174, 2014. DOI: 10.1111/evj.12281.

HAMOND, C.; MARTINS, G.; LOUREIRO, A. P.; BREMONT, S.; MEDEIROS, M. A.; BOURHY, P.; LILENBAUM, W. First isolation and characterization of Leptospira interrogans serogroup Australis from swine un Brazil. Pesquisa Veterina'ria Brasileira, v. 35, p 6-8, 2015. DOI:10.1590/S0100-736X2015000100002. 
HAMOND, C.; PINNA, A.; MARTINS, G.; LILENBAUM, W. The role of leptospirosis in reproductive disorders in horses. Tropical Animal Health and Production, v. 46, p. 110, 2014. http://link.springer.com/article/10.1007\%2Fs11250-013-0459-3.

INSTITUTO TRATA BRASIL. Esgotamento Sanitário inadequado e impactos na saúde da população. Um diagnóstico da situação nos 81 municípios brasileiros com mais de 300 mil habitantes. Disponível em: http://www.tratabrasil.org.br/novo_site/cms/templetes/trata_brasil/files/esgotamento.pdf. 2010. Acesso em: 29 de junho de 2015.

JORGE, M.H.P.M.; LAURENTI, R.; GOTLIEB, S,L,D. Avaliação dos Sistemas de Informação em Saúde no Brasil. Cadernos de. Saúde Coletiva, v.18, p. 07- 18, 2010. http://iesc.ufrj.br/cadernos/images/CSC/2010_1/artigos/modelo\%20livro\%20ufrj\%201a.pdf.

LAVINSKY, M. O.; SAID, R. A.; STRENZEL, G. M. R.; LANGONI, H. Seroprevalence of anti-Leptospira spp. antibodies in dogs in Bahia, Brazil. Preventive Veterinary Medicine, v. 106, p. 79-84, 2012. DOI:10.1016/j.prevetmed.2012.03.015.

LIMA, R. J. S.; ABREU, E. M. N.; RAMOS, F. L. P.; SANTOS, R. D.; SANTOS, D. D. ; SANTOS, F. A. A.; MATOS, L. M.; SARAIVA, J. M. B.; COSTA, A. R. F. Análise da distribuição espaço-temporal da leptospirose humana em Belém, Pará, Brasil. Revsiat Pan-Amazônica de Saúde, v. 3, p. 33-40, 2012. http://dx.doi.org/10.5123/S217662232012000200005.

MACENTE, B.M.; ZANDONADE, E. Avaliação da completude do Sistema de Informação sobre Mortalidade por suicídio na região Sudeste, Brasil, no período de 1996 a 2007. Jornal Brasileiro de Psiquiatria, v.59, p.173- 181, 2010. http://www.scielo.br/pdf/jbpsiq/v59n3/a02v59h3.pdf.

MARTINS, G.; LILENBAUM, W. The panorama of animal leptospirosis in Rio de Janeiro, Brazil, regarding the seroepidemiology of the infection in tropical regions. BMC Veterinary Research, v. 9, p.237, 2013. http://www.biomedcentral.com/1746$\underline{6148 / 9 / 237 .}$

MARTINS, G.; PENNA, B.; LILENBAUM, W. The dog in the transmission of human leptospirosis under tropical conditions: victim or villain? Epidemiology Infecty, v.140, p. 207-209, 2011. DOI:10.1017/S0950268811000276.

MINAYO, M.C.S. Condiciones de vida, desigualdad y salud a partir Del caso brasileño. In: Leon RB, Minyo MCS, Coimbra Junior CE. Salud y equidad: uma mirada de lãs ciências sociales. Rio de Janeiro: Ed. Fiocruz, p. 55-71, 2000.

NAVARRO, M.B.M.A.; FILGUEIRAS A.L.L.; ASENSI, M.C.M.D.; LEMOS, E.; SIDONI , M. Doenças emergentes e reemergentes, saúde e ambiente. In: Saúde e ambiente sustentável: estreitando nós. Rio de Janeiro: Ed. FIOCRUZ, p. 37-39, 2002. 
OLIVEIRA, S. V.; ARSKY, M. L. N. S.; CALDAS, E. P. Reservatórios animais da leptospirose: uma revisão bibliográfica. Saúde (Santa Maria), v. 39, p. 9-20, 2013. http://cascavel.ufms.br/revistas/ojs-2.2.2/index.php/revistasaude/article/view/5094/pdf_1.

OLIVEIRA, D.S.C.; GUIMARÃES, M.J.B.; MEDEIROS, Z. Modelo produtivo para leptospirose. Revista de. Patologia. Tropical, v.38, p. 17-26, 2009. http://dx.doi.org/10.5216/rpt.v38i1.6205.

PELISSARI, D.M.; MAIA-ELKHOURY, A.N.S.; ARSKY, M.L.N.S.; NUNES, M.L. Revisão sistemática dos fatores associados à leptospirose no Brasil, 2000-2009. Epidemiologia e Serviços de Saúde, v.20, p. 565- 574, 2011. DOl:10.5123/S167949742011000400016.

PINNA, M. H.; MARTINS, G.; PINHEIRO, A. C. O.; ALMEIDA, D. S.; ORIÁ, A. P.; LILENBAUM, W. Dectection of ati-Leptospira antibodies in captive nonhuman primates from Salvador, Brazil. American Journal of Primatology, v. 74, p. 8-11, 2012. DOI:10.1002/ajp.v74.1/issuetoc.

SOARES, T.S.M.; LATORRE, M.R.D.O.; LAPORTA, G.Z.; BUZZAR, M.R. Análise espacial e sazonal da leptospirose no município de São Paulo, SP, 1998 a 2006. Revista de Saúde Pública, v.44, p. 283-291, 2010. http://dx.doi.org/10.1590/S003489102010000200008.

SOUZA, V.M.H.; ARSKY, M.L.N.; CASTRO, A.P.B.; ARAÚJO, W.N. Anos potenciais de vida perdidos e custos hospitalares da leptospirose no Brasil. Revista de Saúde Pública, $\quad$ v.45, $\quad$ p.1001-1008, 2011.http://dx.doi.org/10.1590/S0034891020011005000070.

SOUZA, V. M. M.; ARSKY, M. L. N.; CASTRO, A. P. B.; ARAUJO, W. N. Anos potenciais de vida perdidos e custos hospitalares da leptospirose no Brasil. Revista de $\begin{array}{lllll}\text { Saúde } & \text { Pública, } & \text { v. } & 45, & \text { p. }\end{array}$ http://www.scielosp.org/scielo.php?script=sci_arttex\&pid=S0034$89102011000600001 \&$ lng=en\&nrm=iso.

TASSINARI, W.S.; PELLEGRINI, D.C.P.; SABROZA, P.C.; CARVALHO, M.S. Distribuição espacial da leptospirose no município do Rio de Janeiro, Brasil, ao longo dos anos de 1996-1999. Caderno de Saúde Pública, v.20, p.1721-1729, 2004. http://dx.doi.org/10.1590/S0102-311X2004000600031.

VASCONCELOS, C. H.; FONSECA, F. R.; LISE, M. L. Z.; ARSKY, M. L. N. S. Fatores ambientais e socioeconômicos relacionados à distribuição de casos de leptospirose no estado de Pernambuco, Brasil, 2001-2009. Caderno de Saúde Coletiva, v. 20, p. 4956, 2012. http://iesc.ufrj.br/cadernos/imagens/csc/2012_1/artigos/CSC_v20n1_4956.pdf. 
VERMA, A.; STEVENSON, B.; ADLER, B. Leptospirosis in horses. Veterinary Microbiology, v. 167, p. 61-66, 2013. DOI:10.1016/j.vetmic.2013.04.012. 